\title{
İtaki Düşme Öıçeği: Bağımsız Gözlemciler Arası Uyum Çalışması
}

\author{
Itaki Fall Scale: A Study of Independent Inter-Observer Compliance
}

\author{
Ayşe Didem ÇAKIR ${ }^{1}$, Funda BÜYÜKYILMAZ ${ }^{2}$
}

\begin{abstract}
ÖZ
$\mathrm{Bu}$ araștırma, klinik ortamlarda yaygın bir şekilde kullanılan İtaki Düşme Ölçeği’ nin bağımsız gözlemciler arası uyum çalışması ile güvenirliğinin doğrulanması amaciyla yapıldı. Metodolojik türde planlanan çalışma, Kasım 2018 - Ocak 2019 tarihleri arasında bir üniversite hastanesinde gerçekleştirildi. Araştırma; çalışmanın yürütüldüğ̈u üniversite hastanesinde çalş̧an en az lisans düzeyi mezuniyet derecesine sahip olan; araştırmaya gönüllü olarak katılmayı kabul eden, veri toplama araçlarını eksiksiz dolduran 134 hemşire ile çalışma gerçekleștirildi. Araştırmada, hemşirelerin bireysel özelliklerini değerlendirmek amacıyla 'Hemşire Bilgi Formu' kullanıldı. Bağımsız gözlemciler arası uyum değerlendirmesi için de araştırmacılar tarafindan hazırlanan vaka örneği üzerinden 'İtaki Düşme Riski Ölçeği' ni puanlamaları istendi. Araştırma kapsamına alınan hemşirelerin; \%93,3'ünün kadın, yaş

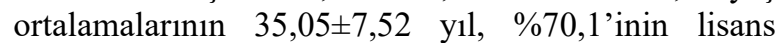
mezunu olduğu, yakın oranlarda dâhiliye $(\% 51,5)$ ve cerrahi $(\% 45,5)$ birimlerde yatak başı hemşiresi olarak $(\% 82,0)$ çalıştı̆̆ saptandı. Hemşirelerin çalışma süreleri kapsamında düşme riski konusunda eğitim aldığı $(\% 56,8)$ ve görev süresinde düşme meydana geldiğinde durumu raporlandırdığı $(\% 80,2)$ belirlendi. İtaki Düşme Ölçeği' ne ilişkin bağımsız gözlemciler arası uyumun pozitif yönde, çok iyi $(0,76)$ düzeyde ve istatistiksel olarak anlamlı bir uyum gösterdiği saptandı ( $\mathrm{ICC}=0,762, \quad \mathrm{p}=0,000$ ). Araştırmada düşme risk puanına göre planladıkları hemşirelik girişimlerinin sonuçlarına göre hemşirelerin; $\% 56,7$ ' si düşme risk tanılaması yapılmasını, \%56,7' sinin çevre yönetimi ile hastanın çevresinin manipüle edilmesini ve $\% 60,4$, ünün yaralanma riski taşıyan hastaya uygun önlemler alınması gerektiğini belirtmişlerdir.
\end{abstract}

Anahtar Kelimeler: Düşme, Risk, Hemşirelik Tanısı, Skala, Gözlemciler Arası Uyum.

\begin{abstract}
This study was conducted to verify the reliability of the Itaki Scale of Falling Scale, which is widely used in clinical settings, with an independent interobserver study. The study, which was planned as a methodological type, was held in a university hospital between November 2018 and January 2019. The study was carried out with 134 nurses who have at least graduate degrees in the university hospital, accepted to participate in the study voluntarily and filled the data collection tools completely. In order to evaluate the individual characteristics of nurses, Nurse Information Form were used. For independent interobserver assessment, Fall Risk Risk Scale was used according to case study developed by researchers. Nurses included in the study; $93.3 \%$ of women, mean age was $35.05 \pm$ 7.52 years, $70.1 \%$ of them were bachelor's degree, worked in internal medicine $(51.5 \%)$ and surgical $(45.5 \%)$ units as bed nurses. (82.0\%). It was determined that the nurses received training on the risk of falling $(56.8 \%)$ within the working hours and reported the situation when the duty time decreased $(80.2 \%)$. It was determined that the inter-observer compliance between the two groups was positive $(0.76)$ and statistically significant (ICC $=0,762, p=0,000)$. According to the results of the nursing interventions that they planned according to the fall risk score in the research; $56.7 \%$ stated that there should be a fall risk diagnosis, $56.7 \%$ of the patients should be manipulated by environmental management and $60.4 \%$ of the patients should be treated with appropriate risk.
\end{abstract}

Keywords: Fall, Risk, Nursing Diagnosis, Scale, InterObserver Compliance.

\footnotetext{
${ }^{1}$ Doktora Öğrencisi, İstanbul Üniversitesi-Cerrahpaşa Lisansüstü Eğitim Enstitüsü, Hemşirelik Esasları Doktora Programı, aysedidemcakir@gmail.com, ORCID: 0000-0002-5489-1887

${ }^{2}$ Doç. Dr (Doktora Tez Danışmanı), İstanbul Üniversitesi-Cerrahpaşa Florence Nightingale Hemşirelik Fakültesi, Hemşirelik Esasları Anabilim Dali, feyilmaz@istanbul.edu.tr, ORCID: 0000-0003-2882-3757

\begin{tabular}{|c|c|c|}
\hline İletişim / Corresponding Author: & Ayşe Didem ÇAKIR & Geliş Tarihi / Received: \\
\hline
\end{tabular}




\section{GÍRIŞ}

Hemşireler; birey, aile ve toplumun sağlığını ve esenliğini koruma, geliştirme ve hastalık durumunda iyileştirme amacına yönelik, bağımsız ve yarı bağımlı işlevlerle uygulamalarını gerçekleştirmektedir. ${ }^{1}$ Hemşirelerin bu işlevlerinde yer alan önemli uygulayıcı rollerinden biri de, birey için güvenli bir ortam oluşturmaktır. ${ }^{2}$

Hastane ortamındaki düşme ve düşme sonucunda oluşan yaralanmalar; hasta, hastanın ailesi, bakım hizmetini sunan sağlık bakım profesyonelleri ve kurum açısından da ciddi bir sorundur. ${ }^{3}$ Düşmeler, hasta güvenliğini tehdit eden ve en sık karşılaşılan sorunların başında yer almaktadır. ${ }^{2}$

Düşme; ağırlık merkezi kaybolduğunda ve dengeyi yeniden kurmak için gösterilen çabaların etkisiz olduğunda ya da hiç çaba sarf edilmediğinde meydana gelir. ${ }^{4}$ Düşme, bireyin yaşamının her döneminde ortaya çıkabilir ama özellikle yaşı bireyler arasında en yaygın yaralanma sebebi olarak kabul edilir. 5,6

Düşme riski; akut ya da kronik hastalıklar, çoklu ilaç kullanımı, denge sorunları, yürümeye yardımcı cihaz kullanımı, görme yetersizliği, bilişsel sorunlar, güçsüzlük ve çevresel tehlikeler yaş ile doğru orantılı olarak artmaktadır. $^{6} \mathrm{Bu}$ nedenle; hastanın gözlenmesi, geçmiş sağlık öyküsü, fiziksel muayenesi ve kullandığı ilaçlar ile laboratuvar sonuçlarının gözden geçirilmesini gerektirir. ${ }^{7}$

Düşme riski özellikle, ileri yaş ve kırılganlık düzeyinin şiddetine göre artış göstermektedir. Bağımlılık düzeyi yüksek olan ve yataklı tedavi kurumlarında bakım gören bireylerin (özellikle yaşlı bireyler) her y1l ortalama \%30-50'sinin düştüğü ve bunlardan \%40'inda düşme durumunun tekrarlandığ 1 raporlandırılmıştır. ${ }^{8}$ Cangany ve arkadaşları (2015), hastanelerde düşme riskini arttıran faktörleri; yabancı ortam olmas1, beden aktivitelerinde değişimler, engellilik, yaşlilarda demans, görme, işitme kaybı, kas kuvveti ve reflekslerde azalma gibi fiziksel ve mental yetersizlikler veya tedavi süreci ile ilişkili uyanıklık durumunu ya da dengeyi etkileyen hastalıklar olarak sıralamaktadır. ${ }^{9}$
Uluslararası Kuzey Amerika Hemşirelik Tanıları Birliği (International North America Nursing Diagnosis - NANDA - I) sınıflamasında 'Düșme Riski'; 'Güvenlik/Korunma' alanı içindeki 'Fiziksel Yaralanma' bölümünde yer almaktadır. NANDA-I düşme riski hemşirelik tanısını; 'fiziksel zararlar ve sağlığ 1 tehdit edebilecek düşmelere karş1 artan eğilim' olarak tanımlamaktadır. Ayrıca çocuk, yetişkin, biyo-fizyolojik ya da bilişsel durum değişikliği olan bireyler, çevresel durum ve farmasötik maddeler ile ilişkili risk faktörleri de NANDA-I tarafindan belirlenmiştir. ${ }^{10}$

Düşmeler, 2004 yılında National Database For Nursing Quality Indicators (NDNQI) tarafindan hastane kalitesinin belirlenmesinde, ilk değerlendirme ölçütlerinden biri olarak belirlenmiştir. $\mathrm{Bu}$ forumda, düşmelerin kontrol altına alınmasının, akut bakım ortamlarında yüksek kalitede bakım sağlamak için önemli olduğunu ve bunun için hemşirelik bakımının anahtar fonksiyonu bulunduğu vurgulamaktadır. ${ }^{11}$

Özellikle bildirilen raporda, hastane ortamında düşmeler ile ilgili prevelansın 1000'de 3,3 ile 11,5 arasında değişiklik gösterdiğini ve ağırlıklı olarak nöroloji, nöroşirürji ve yoğun bakım gibi hastaların bağımlılık düzeylerinin yüksek olduğu yerlerde düşmelerin daha sik oranda gerçekleştiğini belirtmektedir. NDNQI' de, düşmeler olay bildirim raporları ile tanımlanır ve aylık olarak toplam sayı rapor edilir. Düşme ile ilgili yaralanma, olaydan en az 24 saat sonrasına kadar değerlendirilir ve NDNQI' de düşmeler; 'Minör, Orta, Majör' ve hastanın düşmeden kaynaklanan yaralanmalar sonucu öldüğü durum ise; 'Ölüm' şeklinde dört seviyede sınıflandırılır. ${ }^{12}$

Uluslararası Birleşik Komisyonu (Joint Commission International-JCI) 2018'de düşmeyi, hasta güvenliği açısından bir standart olarak belirlemiş ve uluslararası hasta güvenliği hedefleri kapsamında 'hasta düşmelerinden kaynaklanan zararı azaltma' konusuna yer vermektedir. ${ }^{13} \mathrm{Bu}$ bağlamda hastanelerde; hasta bakım yükü, iş gücü ve 
maliyet açısından birçok soruna neden olan düşmelerin önlenmesi için stratejilerin belirlenmesi ve girişimlerin kararlı bir şekilde yürütülmesi adına gerekli planların yapılması ve komitelerin kurulması gerektiği vurgulanmaktadır. ${ }^{14-16}$

Literatürde düşmelerin önlenmesinde; hastaların klinik kabul, ameliyat sonrası erken dönem, klinik ya da birim değişikliği, hastanın düşmesi durumu ve risk etkenlerinde (65 ve üzeri yaş, kronik hastalık varlığı, çoklu ilaç kullanımı, görsel-fiziksel-işitsel engeller, riskli ilaç kullanımı, fazla ekipman varlığı vb.) herhangi bir durum değişikliği saptanması gibi durumlarda tanılama yapılmasının anahtar olduğu belirtilmektedir. ${ }^{17,18} \mathrm{Bu}$ nedenle, düşme risk düzeyi belirlendikten sonra, bireyin güvenliğini kontrol altına alacak gerekli girişimlerin planlanması ve başlatılması esastır. ${ }^{19}$

Bu bağlamda ülkemizde İtaki Düşme Riski Ölçeği, Sağlık Bakanlığı Performans
Yönetimi ve Kalite Geliştirme Daire Başkanlığı tarafından 2011 yılında, Sağlıkta Kalite Standartları'nda hasta güvenliği (yetişkin bireyler için) uygulamalarının bir parçası olarak kabul edilmiş, geçerli bir ölçme aracıdır. ${ }^{20}$ Düşme riskini belirlemek için geçerli ve güvenilir olan ölçeklerin tüm hemşireler tarafından doğru, etkin bir biçimde kullanılması, risk düzeyinin tanılanması, gerekli girişimlerin planlanması ve başlatılmasında oldukça önemlidir. ${ }^{14}$

$\mathrm{Bu}$ araştırma, klinik ortamlarda yaygın bir şekilde kullanılan İtaki Düşme Ölçeği' nin bağımsı gözlemciler arası uyum çalışması ile güvenirliğinin doğrulanması amacıyla planlandi.

Araştırma kapsamında belirlenen soru:

- İtaki Düşme Ölçeği' nin gözlemciler arası uyum düzeyi nasıldır?

\section{Araştırmanın Türü}

$\mathrm{Bu}$ araştırma metodolojik türde yapıldı.

\section{Araştırmanın Yeri ve Zamanı}

Bir üniversite hastanesinde

Kasim 2018 - Ocak 2019 tarihleri arasında gerçekleştirildi.

\section{Araştırmanın Evren ve Örneklemi}

Araştırmanın evrenini; çalışmanın yürütüldüğü üniversite hastanesinde çalışan en az lisans mezuniyet derecesine sahip olan; daha fazla düşme risk puanlandırması uygulayan dahili ve cerrahi birimlerde çalışan hemşireler oluşturdu (N=213). Örneklem büyüklügüünün belirlenmesinde, metodolojik araştırmalar için literatürde değişik görüşler bulunmaktadır. Korelasyon çalışmalarında örneklem sayısı en az 30 olarak belirtilirken, bazı çalışmalarda ise madde sayısının en az 5 veya 10 katı olması gerektiği ifade edilmektedir. ${ }^{21} \mathrm{Bu}$ çalışmada ise; örneklem seçimine gidilmeden, en az lisans mezuniyet derecesine sahip hemşireler örnekleme dahil edildi. $\mathrm{Bu}$ doğrultuda araştırmaya gönüllü olarak katılmayı kabul eden, veri toplama araçlarını eksiksiz dolduran 134 hemşire ile çalışma gerçekleștirildi. Çalışma anketlerinin yanitlanma oran $\% 62,9$ olarak belirlendi.

Araştırmanın, örnek vaka üzerinden zaman sinırlamas1 olmadan yapılmas1 ve tek bir üniversite hastanesinde uygulanması genellenebilirliği açısından sınırlılık olarak kabul edildi. Sınırlılıklardan bir diğeri de; düşme riskinin tanılanmasının hemşirelere verilen vaka örneği doğrultusunda, açık uçlu değerlendirme üzerinde analiz yapılmasıdır.

\section{Veri Toplama Araçları}

Araştırmada hemşirelerin bireysel özelliklerini değerlendirmek amacıyla 'Hemşire Bilgi Formu' ve bağımsız gözlemciler arası uyum değerlendirmesi için de 'İtaki Düşme Riski Ölçeği' kullanıldı.

\section{Hemşire Bilgi Formu}

$\mathrm{Bu}$ form, hemşirenin tanıtıcı özellikleri (yaş, cinsiyet, eğitim düzeyi, görev yapılan birim, pozisyonu) ve düşme riski konusunda 
bilgi alma, düşmeleri raporlandırma durumlarını içeren sorulardan oluşturuldu.

\section{İtaki Düşme Risk Ölçeği}

17 yaş ve üzerindeki hastalar için oluşturulmuş olan bu ölçek, hasta demografik bilgilerini, değerlendirme yapma nedenini, major ve minör risk faktörlerini içermektedir. Ölçekte Major Risk Faktörleri (8), Minör Risk Faktörleri (11) başlıkları altında toplam 19 madde mevcuttur. Ölçek skoru tüm maddelerin aldığı puanlar toplanarak oluşturulur. Toplam skor 0-4 puan arasında ise düşük risk; 5 puan ve üzerinde ise düşme açısından yüksek risk kabul edilir. ${ }^{20}$

\section{Verilerin Toplanması}

Bağımsız gözlemciler arası durum değerlendirmesi için, araştırmacılar tarafından ilgili literatür doğrultusunda geliştirilen vaka üzerinden, hemşirelerin düşme risk puanlaması yapmaları ve ilgili vakanın düşme risk puanına göre, planladıkları hemşirelik girişimlerini listeleyerek, yazmaları istendi. Veriler, hemşirelerin işlerini aksatmamaları için dinlenme zamanlarında toplandı. Vaka tanıtımı ve sorular ise sorumlu araştırmacı tarafından yüz-yüze görüşme yöntemi ile hemşirelere açıklandı. Bir vakanın analizi ortalama 30-35 dk. 'lık bir sürede tamamlandı.

\section{Vaka Örneği}

84 yaşında olan Bayan E.R., bekar, 15 senedir diyabet hastalığı nedeniyle insülin kullanıyor, son zamana kadar erkek kardeşi ile yaşıyordu. Kardeşi, yaklaşık 6 ay önce vefat eden Bayan E.R. şuan yalnız yaşamaktadır. Bayan E.R., evde çalan telefona yetişmek için hızlıca hareket ettiği sırada düştüğünü belirtti ve acil bakım ekiplerince düştüğü yerde birkaç saat hareketsiz kaldığı belirlendi.

Düşme sonucu gittiği Acil Servis’ten hasta servisine nakledildi. Siz, Bayan E.R.'yi servise kabul esnasında hasta dosyasından kemik yaralanması olmadığını öğrendiniz; ancak Bayan E.R.'nin etkilenen bölgesinde ekimozu var ve kendisi stresli görünüyor. Yatak içinde hareket etmeye çalıştığında kendini sabit tutamiyor, titriyor. Hasta servisinde antikoagülan tedaviye başland, IV kateteri var ve zaman zaman da solunum desteği için nazal kanülden oksijen uygulanıyor. Yatak içinde hareketini kendisi gerçekleştirirken, yatak dışında dengesini sağlayamadığ 1 ve ortostatik hipotansiyon riski nedeniyle hemşire desteği ile ayağa kalkabiliyor. Bayan E.R., yardım almadan tuvalete giderken düştü.

Şuan sağ kalçasında ve bacağında şiddetli bir ağr1 şikâyeti var. Aşırı solgun ve korkmuş görünüyor. Taşikardisi olduğu (180/dk), solunum sayısının yüksek (32/dk) ve hipotansiyonu $(90 / 60 \mathrm{mmHg})$ olduğu tespit edildi. Bayan E.R. să̆ bacağını kendi iradesiyle oynatamadiğ 1 , ancak koopere olduğu belirlendi. Gözlem sirasında, sağ bacağının kısalmış ve dışa dönmüş görünüyor. Hekimi tarafindan yapilan ilk değerlendirmede Bayan E.R.'nin sağ femur başı kırığı olduğu belirlenerek, ameliyata alınd. Ameliyat sonrası dönemde kesin yatak istirahatine alınan Bayan E.R.'nin, foley kateteri ve IV kateteri bulunmaktadır. Hareket k1sitlamas1 devam eden Bayan E.R.'nin konuşma yeteneğinde azalma, sözcükleri tam ve açık söyleyememe ile zaman zaman konfüze olduğu, zamana ve yere karş1 oryantasyon bozukluğu geliştiği saptandı ve bu durumuna yönelik tedavisi hekimi tarafindan planlandi.

$\mathrm{Bu}$ bilgiler doğrultusunda hemşirelerden, ameliyat sonrası dönem için düşme riskini puanlamaları ve hasta güvenliğini sağlamak için planladıkları hemşirelik girişimlerini yazmaları istendi.

\section{Verilerin Değerlendirilmesi}

İstatiksel analizler için İstanbul Üniversitesi-Cerrahpaşa lisanslı IBM SPSS Statistics 20 programı kullanıldı. Tanımlayıc1 istatistikler (ortalama, standart sapma, frekans) ve gözlemciler arası güvenirlik değerlendirmesi sınıf içi korelasyon katsayısı (Intraclass Correlation Coefficient-ICC) ile değerlendirildi.

Gözlemciler arası veya gözlemci içi uyumun değerlendirilmesinde, ölçümler sürekli olduğunda Sınıf İçi Korelasyon Katsayısı (ICC) kullanılır. ${ }^{22}$ Barrett, Sınıf İçi Korelasyon Katsayıs1 kabul edilebilir seviyeleri zayıf $=<0,40$; orta $=0,40-0,59$; iyi $=$ 
0,60-0,74; çok iyi $=>0,74$ olarak belirtmiştir. Yapılan çalışmalarda, yaklaşık 0,70- 0,80' in üzerindeki değerler kabul edilebilir. $\mathrm{Bu}$ değerin altındaki derecelendirme verilerini kullanmaktan kaçınılır. ${ }^{23,24}$ Anlamlılık düzeyi $\mathrm{p}<0,05$ olarak kabul edildi.

\section{Araştırmanın Etik Yönü}

Araştırmanın yapılabilmesi için İstanbul Üniversitesi-Cerrahpaşa Cerrahpaşa Tip Fakültesi Hastanesi'nden (21.09.2018 tarihli /62314 say1li) kurum izni, İstanbul Üniversitesi-Cerrahpaşa Cerrahpaşa Tıp
Fakültesi Hastanesi Klinik Araştırmalar Etik Kurul'undan (07.11.2018 tarihli/88264 say1lı) etik izin ve araştırmaya katılmayı kabul eden hemşirelerden bilgilendirilmiș gönüllü olur alındı. Araştırma kapsamında kullanılan İtaki Düşme Riski Ölçeği, Sağlık Bakanlığı Performans Yönetimi ve Kalite Geliştirme Daire Başkanlığ 1 tarafından geliştirilmiş olup; tüm sağlık kurumlarının eğitim, araştırma ve uygulama faaliyetlerinde kullanımı için hazırlanmıștır. Ölçek kullanımı herkese açıktır ve erișim izni web sayfada sunulmaktadır. ${ }^{20}$

\section{BULGULAR VE TARTIŞMA}

Araştırma kapsamına alınan hemşirelerin; \%93,3'ünün kadın, yaş ortalamalarının $35,05 \pm 7,52$ y1l, \%70,1'inin lisans mezunu olduğu, yakın oranlarda dâhiliye $(\% 51,5)$ ve cerrahi $(\% 45,5)$ birimlerde yatak baş1 hemşiresi olarak $(\% 82,0)$ çalıştı̆̆ saptandı. Hemşirelerin çalışma süreleri kapsamında düşme riski konusunda eğitim aldığ $1(\% 56,8)$ ve hasta düşme durumlarını raporlandırdığ 1 $(\% 80,2)$ belirlendi (Tablo 1).

Çalışmada tanılama yapmaları istenen vakaya göre hemşirelerin; \%56,7' si düşme risk tanılaması yapılması gerektiğini, \%56,7' sinin çevre yönetimi ile hastanın çevresinin manipüle edilmesi gerektiğini ve $\% 60,4$, ünün yaralanma riski taşıyan hastaya özel önlemler alınması gerektiğini belirtmişlerdir (Tablo 2).

Ancak, düşme riski ile ilgili raporlandırmanın önemini bilen $(\% 80,2)$, hemşirelerin; düşmeyi önleme, çevre yönetimi ve risk tanılanması için planladıkları girişimlerde sınırlı oranda farkında oldukları görüldü. Hemşirelerin bilgi eksikliği nedeniyle gerekli önlemleri almaması; hasta güvenliğini olduğu kadar, yasal açıdan hemşireleri de zor durumda bırakan bir durum olarak değerlendirildi.
Tablo 1. Hemşirelerin Sosyo-Demografik Özellikleri ve Düşme Riski ile İlgili Bilgi Durumları (N=134)

\begin{tabular}{|c|c|c|}
\hline $\begin{array}{l}\text { Sosyo-Demografik } \\
\text { Özellikleri ve Düşme Riski } \\
\text { İle İlgili Bilgi Durumları }\end{array}$ & $\mathbf{n}$ & $\%$ \\
\hline $\begin{array}{ll}\text { Yaş } & \text { Ort } \pm \mathrm{SS}=35,05 \pm 7,52 \\
51)\end{array}$ & (Min-m & $\mathrm{x}=21-$ \\
\hline \multicolumn{3}{|l|}{ Cinsiyet } \\
\hline Kadın & 125 & 93,3 \\
\hline Erkek & 9 & 6,7 \\
\hline \multicolumn{3}{|l|}{ Görev Yapılan Birim } \\
\hline Dâhiliye Servisi & 69 & 51,5 \\
\hline Cerrahi Servisi & 61 & 45,5 \\
\hline Hayır & 26 & 19,8 \\
\hline \multicolumn{3}{|l|}{ Eğitim Durumu } \\
\hline Lisans mezunu & 94 & 70,1 \\
\hline Lisansüstü mezunu & 40 & 29,9 \\
\hline \multicolumn{3}{|l|}{ Görev Pozisyonu } \\
\hline Yatak başı hemşiresi & 109 & 82,0 \\
\hline $\begin{array}{l}\text { Sorumlu/Yönetici } \\
\text { hemșire }\end{array}$ & 24 & 18,0 \\
\hline \multicolumn{3}{|l|}{$\begin{array}{l}\text { Düşme Riski Konusunda } \\
\text { Durumu }\end{array}$} \\
\hline Evet & 75 & 56,8 \\
\hline Hayır & 57 & 43,2 \\
\hline $\begin{array}{l}\text { Hasta Düsşmelerinin } \\
\text { Durumları }\end{array}$ & \multicolumn{2}{|c|}{ Raporlandırma } \\
\hline Evet & 105 & 80,2 \\
\hline Hayır & 26 & 19,8 \\
\hline
\end{tabular}


Tablo 2. Düşme Riski Puanı'na Göre Planlanan Hemşirelik Girişimleri*

\begin{tabular}{lrr}
\hline $\begin{array}{l}\text { Planlanan Hemşirelik } \\
\text { Girişimleri** }\end{array}$ & n & \% \\
\hline $\begin{array}{l}\text { Düşmeyi Önleme: Düşme } \\
\text { nedeniyle yaralanma riski } \\
\text { taşıyan hasta ile birlikte özel }\end{array}$ & 1 & 60, \\
$\begin{array}{l}\text { önlemler alınacak } \\
\text { Çevre Yönetimi: Güvenlik: }\end{array}$ & 13 & 56, \\
$\begin{array}{l}\text { Terapötik yararları için hastanın } \\
\text { çevresi manipüle edilecek }\end{array}$ & 2 & 7 \\
$\begin{array}{l}\text { Risk Tanılama: Olası risk } \\
\text { faktörlerinin analizi, sağlık } \\
\text { risklerinin belirlenmesi, } \\
\text { birey/grup için risk azaltma } \\
\text { stratejilerinin } \\
\text { önceliklendirilmesi sağlanacak }\end{array}$ & 7 & 56, \\
\end{tabular}

*Nursing Intervention Classification (NIC) Sinflama Sistemi Türkçe versiyonu kullanılmıștır.

**Birden fazla yanit verilmiştir

İtaki Düşme Risk Ölçeği’ ne ilişkin bağımsız gözlemciler arası uyumun pozitif yönde, çok iyi $(0,76)$ düzeyde ve istatistiksel olarak anlamlı bir uyum gösterdiği saptandı (ICC $=0,762, \quad p=0,000)$. Ölçeğin kapsam geçerlilik indeksi 1 olarak belirlendi (Tablo $3)$.

Tablo 3. İtaki Düşme Ölçeği'ne İliş̧in Bağımsız Gözlemciler Arası Güvenirlik Değerlendirmesi

\begin{tabular}{|c|c|c|c|}
\hline İstatistiksel Analiz & $\begin{array}{l}\text { İtaki } \\
\text { Ölçeği }\end{array}$ & Düşme & Risk \\
\hline ICC* & & & 0,762 \\
\hline \multicolumn{4}{|l|}{$\% 95$ GA } \\
\hline Alt sınır & & & 0,613 \\
\hline Üst sınır & & & 0,843 \\
\hline$p$ & & & $0,000 * *$ \\
\hline
\end{tabular}

Hemşireler düşme riskini doğru belirleyebilmek için geçerli ve güvenilir değerlendirme araçlarını seçmelidirler. Düşmeyi önlemek için bir değerlendirme aracı seçmeden önce hemşirelerin bu ölçme aracının kullanımını ve özelliklerini öğrenmesi gerekir. ${ }^{25}$

Sağlık alanında yapılan güvenirlilik çalışmalarında, en yaygın olarak gözlemci içi ve gözlemciler arası uyum yöntemleri kullanılır. $^{22}$ Gözlemciler arası güvenirlik, aynı ölçme aracı kullanıldığında elde edilen puanların bir gözlemciden diğer gözlemciye değişmemesi olarak ifade edilir. ${ }^{26}$ Bağımsız gözlemciler arası uyum aynı durumu değerlendiren birbirinden bağımsız iki ya da daha fazla gözlemci olduğunda hesaplanabilmektedir. ${ }^{27}$

Hesaplamalar sonrasinda elde edilen güvenirlik değeri; birbirinden bağımsız gözlemcilerin aynı durum değerlendirmesinde ne kadar uyum içinde olduklarını göstermektedir. ${ }^{28}$

$\mathrm{Bu}$ çalışmanın sonucunda; bağımsız gözlemciler arası uyumun sınıf içi korelasyon katsayısı 0,762 olarak bulunmuştur. Bu değer bağımsız gözlemciler arası uyumun 'çok iyi' olduğunu göstermektedir. Çalışmamızda, düşme riski ile ilgili durumun tanılanması örnek vaka örneği üzerinden yapılmıştır. Ancak klinikte deneyimlenen düşme riskine ilişkin gerçek durumların tanılanması ve gerekli girişimlerin planlanması daha özellikli bir durum olacaktır.

$\mathrm{Bu}$ nedenle, örnek vakanın daha geniş/rahat bir zaman diliminde değerlendirilmesiyle elde edilen skorların, uyum sonucunu arttırdığı düşünülmektedir.

\section{SONUÇ VE ÖNERILER}

Çalışmamızın sonucunda; bağımsız gözlemciler arası uyumun 'çok iyi' olduğu, ancak hemşirelerin düşme riskinin tanılanması ve gerekli güvenlik önlemlerinin alınması konusunda bilgi eksikliklerinin olduğu tespit edildi.
Hemşireler düşme riskini ve risk faktörlerini doğru belirlemek için kanıta dayalı güvenilir risk değerlendirme ölçekleri ve tanılama yöntemlerini kullanmalıdır. $\mathrm{Bu}$ değerlendirmelerin sonucunda belirlenen risk faktörlerine göre güvenlik önlemleri alınarak, düşme riskinin azaltılacağı ve önlenebilir 
düşmelerin önüne geçilebileceği düşünülmektedir.

Düşmelerin önlenmesinde klinik ortamlarda yaygın bir biçimde kullanılan düşme risk ölçeklerinin, daha etkili ve bilinçli bir yöntem olarak kullanılabilmesi için, benzer bilimsel çalışmalar daha geniş örneklem gruplarına uygulanmalıdır.

\section{KAYNAKLAR}

1. Öztunç, G. (2013). Hemşireliğin Doğası İçinde: Hemşirelik Esasları. Hemșirelik Bilim ve Sanatı. Aștı, T, Karadağ, A. (Ed). Akademi Basın ve Yayıncilık, İstanbul, 25-37.

2. Koh, S.S.L., Manias, E., Hutchinson, A.M., Donath, S. Johnston, L. (2008). Nurses' perceived barriers to the implementation of a fall prevention clinical practice guideline in singapore hospitals. BMC Health Services Research, 8, 105-113.

3. Spoelstra, S., Given, B., Given, C. (2011). Fall prevention in hospitals: An integrative review. Clinical Nursing Research, 21 (1), 92-112.

4. Ungar, A., Rafanelli, M., Iacomelli, I., Brunetti, M.A., Ceccofiglio, A., Tesi, F., et. al. (2013). Fall prevention in the elderly. Cilinical Cases in Mineral and Bone Metabolism, 10 (2), 91-95

5. Sharif, S. I., Al-Harbi, A. B., Al-Shihabi, A. M., Al-Daour, D. S., Sharif, R. S. (2018). Falls in the elderly: Assessment of prevalence and risk factors. Pharmacy Practice (Granada), 16 (3), 1206.

6. Oksel, E. (2018). Düşmeye hemşire bakışı ve değerlendirilmesi. Aegean Journal of Medical Science, 4,140-142.

7. Quigley, P. (2016). Evidence levels: Applied to select fall and fall injury prevention practices. Rehabilitation Nursing, 41 (1), $5-15$

8. World Health Organization (WHO) Ageing, \& Life Course Unit (2008). In: WHO Global Report on Falls Prevention in Older Age. WHO Book, Switzerland, 1-12.

9. Cangany, M., Back, D., Hamilton-Kelly, T., Altman, M., Lacey, S. (2015). Bedside nurses leading the way for falls prevention: An evidence-based approach. Critical Care Nurse, 35 (2),82-4.

10. Turan, N. (2017). Hareket. İçinde: Hemsirelik Tanıları Tanımlar ve Sınıflandırma 2015-2017. Acaroğlu, R., Kaya, H. (Çeviri Ed). Nobel Tip Kitabevi, İstanbul, 384.

11. National Database for Nursing Quality Indicators: Definition of a fall. (2013).

http://www.nursingquality.org/Content/Documents/NQF-Data Collection-Guidelines.pdf. Erişim Tarihi: 20.11.2019

12. Bouldin, E., Andresen, E., Dunton, N., Simon, M., Waters, T., Liu, M., et al. (2013). Falls among adult patients hospitalized in the United States: Prevalence and trends. Journal of Patient Safety, 9(1), 13-17.

13. Joint Commission International (JCI) (2018). International Patient Safety Goals.

https://www.jointcommissioninternational.org/improve/internat ional-patient-safety-goals/ Erişim Tarihi: 07.01.2020

14. Aranda-Gallardo, M., Morales-Asencio, J.M., Canca-Sanchez J.C., Barrero-Sojo, S., Perez-Jimenez, C., Morales-Fernandez, A., et al. (2013). Instruments for assessing the risk of falls in acute hospitalized patients: A systematic review and metaanalysis. BMC Health Service Research, 2 (13), 122.

15. Brown, C.J., Rebecca, R.S. (2014). Hospital Falls. In: Patient Safety: A Case-Based Comprehensive Guide. Agrawal, A. (Ed). Springer, New York,197-211.
16. Titler, M.G., Conlon, P., Reynolds, M.A., Ripley, R., Tsodikov, A., Wilson, D.S., et al. (2016). The effect of a translating research into practice intervention to promote use of evidencebased fall prevention interventions in hospitalized adults: A prospective pre-post implementation study in the US. Applied Nursing Research, 31, 52-59.

17. Oliver, D., Healey, F. (2009) Falls risk prediction tools for hospital inpatients: Do they work? Nursing Times, 105 (7), 1821.

18. T.C. Sağlık Bakanlığı Sağlık Hizmetleri Genel Müdürlüğü İtaki Düşme Riski Ölçeği (2017). https://kalite.saglik.gov.tr/TR,13486/itaki-dusme-riskiolcegi.html Erişim Tarihi: 12.08.2018

19. Oliver, D., Connelly, J., Victor, C., Shaw, F., Whitehead, A., Genc, Y., et al. (2007). Strategies to prevent falls and fractures in hospitals and care homes and effect of cognitive impairment: Systematic review and meta-analyses. British Medical Journal, 334(7584), 82-86.

20. Tanıl, V., Çetinkaya, Y., Sayer, V., Avşar, D., İskit, Y. (2014). Evaluating fall risk. Health Care Academy Journal, 1 (1), 21-26.

21. Talbot, L.A. (1995). Principles and Practice of Nursing Research. Mosby-year book, St. Louis.

22. Ates, C., Öztuna, D., Genç, Y. (2009). Sağlık araștırmalarında sınıf içi korelasyon katsayısının kullanımı. Türkiye Klinikleri Journal of Biostatistics, 1 (2), 59-64.

23. Barrett, P. (2001). Assessing the reliability of rating data https://www.pbarrett.net/presentations/rater.pdf. ErişimTarihi: 15.12.2019

24. Karaca, A., Demirci, N. (2019). Adölesan Sedanter Aktivite Anketi (ASAA)' nin 11 ile 14 yaş arasındaki adölesanlarda geçerlik ve güvenirlik çalıșması. Spor Hekimliği Dergisi, 54 (4), 255-266.

25. Ryan, J. (2008). Mobilizing. In: applying the Roper Logan Tierney Model in Parctice. Holland, K., Jenkins, J., Solomon, J., Whittam S. (Ed). Elseiver, London, 317-354.

26. Kutlu, Ö., Doğan, D., Karakaya, İ. (2009). Öğrenci başarısının belirlenmesi: Performansa ve portfolyaya dayalı durum belirleme. Pegem Akademi, Ankara.

27. Viere, J., Garrett, M. (2005). Understanding interobserver agreement: The Kappa statistic. Family Medicine, 37 (5), 360362.

28. Bilgen, Ö., Doğan, N. (2017). Planlayıcılar arası güvenirlik belirleme tekniklerinin karşılaştırılması. Eğitimde ve Psikolojide Ölçme ve Değerlendirme Dergisi, 8 (1), 63-78. 